\title{
Large effects of small pressure changes in the kinetics of low pressure glow discharges
}

\author{
$\underline{\text { Isabel Tanarro }}{ }^{*}$, Víctor J. Herrero \\ Inst. de Estructura de la Materia, CSIC \\ Serrano 123, 28006 Madrid, Spain \\ ${ }^{(*)}$ itanarro@iem.cfmac.csic.es
}

\begin{abstract}
The effect of comparatively small pressure changes on the composition of low pressure hollow cathode DC discharges is investigated with a combination of experimental diagnostic techniques and simple models of the plasma kinetics. The plasma precursors considered are $\mathrm{H}_{2}, \mathrm{Ar} / \mathrm{H}_{2}$ mixtures, and air. In all cases, sudden characteristic composition changes are observed in the pressure interval between $\approx 0.5$ and $3 \mathrm{~Pa}$. Focusing the analysis on these distinctive changes has revealed most useful for the identification of key physicochemical processes in the various plasmas investigated.
\end{abstract}

\section{Introduction}

Glow discharges are widely used in spectroscopic studies of excited levels or kinetics of highly reactive species (radicals and ions), which play a key role in the gas phase chemistry of combustion [1] or in remote regions of interstellar space [2,3] and planetary ionospheres [4]. They find also widespread application in elemental analysis [5] and in a variety of technological processes [6], like sputtering [7], thin film processing [8,9] plasma sterilization [10], and controlled fusion devices, where they are employed for wall conditioning and cleaning [11-14].

The chemical kinetics of the cold plasmas produced in glow discharges is ultimately determined by the disequilibrium between the high temperature of the light electrons (1-10 $\mathrm{eV})$ and the much lower temperature $(<0.1 \mathrm{eV})$ of the heavy species (neutrals and ions). Glow discharges are stable over a pressure range determined by the suitable conditions for electron acceleration and multiplication in collisions with gas particles. The pressure of the gas determines the electron temperature and free charge density, the frequency of binary 
collisions, the importance of surface vs. gas-phase processes and the characteristics of the plasma sheath. The chemical composition of glow discharges evolves often gradually with pressure, but sometimes abrupt changes are observed within a comparatively small pressure interval. In this work, we will show that these more sudden changes and, in particular, the crossing points between the relative concentrations of plasma components, can provide valuable clues about the variation in the comparative importance of the key physicochemical mechanisms determining the discharge properties. To this aim, we will use results derived from the diagnostics and modeling of hollow cathode DC glow discharges. It should be stressed at this point, that the mentioned changes in chemical composition do not affect the overall discharge regime, which works all time in the hollow cathode mode with currents and voltages that evolve smoothly with pressure over the range studied

The discharge precursors considered are $\mathrm{H}_{2}$, mixtures of $\mathrm{H}_{2} / \mathrm{Ar}$, and air. All the plasmas studied here were produced at pressures from tenths of $\mathrm{Pa}$ to a few $\mathrm{Pa}$. For the dimensions of our reactor, the pressure range sampled stretches from the minimum density required to sustain the discharge, which depends slightly on the nature of the plasma precursors and corresponds to the highest electronic temperatures, to a condition where two-body homogeneous reactions between ions and neutrals become relevant in the negative glow.

The analysis of the results, in the light of simple kinetic models, shows that the brusque composition changes observed in the plasmas do not have a single physical cause, but can be brought about by different types of processes, which depend on the particular discharge investigated. The paper is organized as follows: Sections 2 and 3 describe the experimental set up and the basic details of the kinetic modeling respectively; section 4 contains the most relevant experimental results and model analyses for the three plasmas investigated, and finally, the main conclusions are summarized in section 5.

\section{Experimental set-up}

The experimental set-up has been described in detail in previous publications $[15$, 16] and only a brief account of its most relevant features is given here. The plasma reactor consists of a grounded stainless-steel cylindrical vessel $(10 \mathrm{~cm}$ diameter, $34 \mathrm{~cm}$ length) acting as cathode, with several vacuum flanges for gas input and output and plasma sampling, and a central anode. It is continuously pumped by a turbomolecular 
pump backed by a dry pump to a background pressure of $10^{-5} \mathrm{~Pa}$. A butterfly vacuum valve at the exit of the reactor and various needle valves at the gas inputs are used for the control of the pressure, flow rates, and relative concentrations of the gases in the discharge mixtures.

Gas pressures $\sim 0.5-3 \mathrm{~Pa}$ were employed for plasma generation. Direct plasma currents $\sim 150 \mathrm{~mA}$ and voltages $\sim 300-450 \mathrm{~V}$ (depending on gas composition and pressure) in abnormal glow discharge conditions were maintained during the experiments. Under these conditions, the glow region of the plasma, characterized by an electric field $E \approx 0$, has a cylindrical shape occupying a volume, $\mathrm{V}_{\mathrm{p}}$, separated by a sheath with a typical width of 1-2 cm from the cathode walls [17], which define the reactor volume, $\mathrm{V}_{\mathrm{r}}$.

Electron temperatures and densities were measured with a double Langmuir probe and had typical values of $\mathrm{T}_{\mathrm{e}}=3-8 \mathrm{eV}$ and $\mathrm{n}_{\mathrm{e}} \approx 10^{10} \mathrm{~cm}^{-3}$ for the plasmas considered, assuming that only positive ions are formed in the discharge. A differentially pumped Balzers PPM421 Plasma Process Monitor with an energy analyzer, a quadrupole mass filter, and an electron multiplier was used for the detection of ions, which were extracted directly from the plasma through a $100 \mu \mathrm{m}$ diameter sampling orifice in the cathode. Absolute ionic concentrations were obtained by equating the sum of concentrations of all the positive ions to the electron densities. An electron bombardment ionizer placed before the energy analyzer is also available for the detection of neutrals. Neutrals were alternatively detected with an additional quadrupole mass spectrometer (Balzers-Prisma) in a separately pumped chamber. Optical emission spectroscopy, in combination with collisional radiative models, was used to determine the internal temperatures and dissociation degree of $\mathrm{H}_{2}[15,18-20]$

\section{Kinetic models}

For the analysis and interpretation of the experimental results, we have applied zero order kinetic models $[15,21,22]$. The models are based on the numerical integration of the set of coupled differential equations relevant for each case, and the integration is carried out from the ignition of the discharge to the attainment of the steady state. The models assume that very reactive or unstable species like electronically excited atoms, ions or radicals, are restricted to the plasma volume, $V_{p}$, and that stable species occupy the whole reactor, $\mathrm{V}_{\mathrm{r}}$. It is further assumed that electron temperatures and densities are 
homogeneous throughout the glow, and the measured $T_{e}$ and $n_{e}$ values are taken as input parameters. The use of this homogeneous $T_{e}$ assumes implicitly a Maxwellian electron energy distribution and constitutes an approximation, since the actual distribution is strictly non-Maxwellian and non-local.

The models contemplate chiefly electron impact dissociation and ionization, gasphase bimolecular reactions between reactive species (ions, radicals) and molecules, wall neutralization of ions, and heterogeneous reactions. Bimolecular reactions of stable molecules or three body processes in the gas phase are disregarded, since they are unimportant for the temperatures and pressures of our plasmas. The presentation of this article is restricted to the key processes determining the most salient composition changes. For a complete set of chemical reactions, the reader is referred to Refs $[15,21$, 22]

A significant improvement to the model for $\mathrm{H}_{2}$ plasmas included in the present work has been the introduction of a differential equation describing consistently the evolution of $\mathrm{H}^{+}$, instead of using the electroneutrality condition to derive the concentration of this ion, as was done in Ref. [15]. A critical analysis has shown that some of the processes included in the earlier versions of the models [15, 21], like electron impact neutralization, were irrelevant for our plasma conditions and could be removed.

\section{Results and discussion}

\subsection{Hydrogen plasma}

The chemistry of pure hydrogen plasmas is initiated by electron impact ionization and dissociation of the $\mathrm{H}_{2}$ molecules, which leads primarily to $\mathrm{H}^{+}$and $\mathrm{H}_{2}{ }^{+}$ions and to $\mathrm{H}$ atoms. $\mathrm{H}_{3}{ }^{+}$is then produced through the ion-molecule reaction of $\mathrm{H}_{2}^{+}$with $\mathrm{H}_{2}$, and wall processes at the cathode lead to ion neutralization and to $\mathrm{H}$ atom recombination. The basic

processes are listed in Table 1. Negative $\mathrm{H}^{-}$ions could, in principle, be formed by dissociative electron attachment to $\mathrm{H}_{2}$ molecules in highly excited vibrational levels ( $v>7$ ), but for the vibrational temperature of our plasmas (3000 K), derived from emission spectroscopy measurements [15], the population of these levels is extremely low. Measurements of $\left[\mathrm{H}^{-}\right]$in hollow cathode plasmas containing $\mathrm{H}_{2}[23]$ suggest that $\mathrm{H}^{-}$should account for less than $1 \%$ of the negative charge carriers and we have not considered these 
ions. Over the narrow 0.8-2 $\mathrm{Pa}$ range, the relative ion concentrations change markedly from plasmas dominated by $\mathrm{H}_{2}{ }^{+}$to others where $\mathrm{H}_{3}{ }^{+}$is the major ion, as shown in Figure 1a. In a previous work [15], we had assumed that the increase in pressure, and thus in the number of binary collisions, was the main cause of the change in the $\mathrm{H}_{3}{ }^{+} / \mathrm{H}_{2}{ }^{+}$ratio, due to the high efficiency of reaction R5. Notwithstanding the growing importance of reaction R5 with gas density, a careful analysis shows that the key factor determining the crossing point between the relative concentrations of $\mathrm{H}_{2}{ }^{+}$and $\mathrm{H}_{3}{ }^{+}$is the strong dependence of $\mathrm{T}_{\mathrm{e}}$ on pressure (Figure 1b), reflecting the decrease in the efficiency of electron energy thermalization with growing rarefaction. This effect is illustrated in Figure 2, where the relevant rate coefficients are represented as a function of electron temperature. The coefficients for electron impact ionization of $\mathrm{H}_{2}(\mathrm{R} 2$ and $\mathrm{R} 3)$ increase markedly with growing $\mathrm{T}_{\mathrm{e}}$. For electronic temperatures higher than $\approx 6.5 \mathrm{eV}$, which correspond to the lower pressure range investigated, the rate coefficient for the ionization process R3 leading to $\mathrm{H}_{2}{ }^{+}$is larger than that for reaction $\mathrm{R} 5$ destroying $\mathrm{H}_{2}{ }^{+}$. Below this $\mathrm{T}_{\mathrm{e}}$ value, the trend is inverted and the chemical reaction prevails over electron impact ionization. Taking into account that reactions $\mathrm{R} 3$ and $\mathrm{R} 5$ are the principal source and sink of $\mathrm{H}_{2}{ }^{+}$respectively, one can expect that the electronic temperature corresponding to the observed crossing of their rate coefficient values can be determinant for the relative steady state concentrations of $\mathrm{H}_{2}{ }^{+}$and $\mathrm{H}_{3}{ }^{+}$in the plasma and, in fact, comparison between figures 1 and 2 corroborates this conclusion. It should be noted that in all cases the primary ion formed at the ignition of the discharge is $\mathrm{H}_{2}{ }^{+}$, but the initial concentration of this ion decreases rapidly, as can bee seen in figures $3 \mathrm{a}$ and $3 \mathrm{~b}$, where the time-resolved model results for the two extreme cases considered (at 0.8 and $2 \mathrm{~Pa}$ respectively) are displayed as solid curves. According to the model predictions, the major ions $\mathrm{H}_{2}{ }^{+}$and $\mathrm{H}_{3}{ }^{+}$reach virtually their steady state concentrations in $\mu$ s and the $\mathrm{H}^{+}$and the neutral species evolve in a much slower way. The steady-state experimental values are also represented as small circles at the right end of the figures.

The fraction of $\mathrm{H}$ atoms in the plasma, estimated from emission spectroscopy measurements $[15,20]$, is appreciable and remains approximately constant $\left(\mathrm{H} / \mathrm{H}_{2} \approx 0.1\right)$ over the pressure range considered. A crucial process controlling the concentration of $\mathrm{H}$ atoms is wall recombination, R6, characterized by the non-dimensional probability of recombination coefficient, $\gamma$. The present measurements, in conjunction with the kinetic model, allow a determination of this coefficient as exemplified in figure 4, where the calculated evolution of the $\mathrm{H}$ and $\mathrm{H}_{2}$ concentrations is given as a function of $\gamma$. Our results 
favor a small value $\gamma=0.03$, in agreement with Tserepi and Miller [24], and are incompatible with the much larger value $(\gamma=0.2)$ of Kae-Nune et al. [25]. The improvements in the kinetic model, mentioned above, have also shown that a significant proportion of the $\mathrm{H}$ atoms in the plasma $(10 \%$ at $2 \mathrm{~Pa}$ and up to $40 \%$ at $0.8 \mathrm{~Pa})$ is produced in processes involving ions (gas phase reaction R5 and wall neutralization processes R7 and R9).

\section{4. $2 \mathrm{H}_{2}$ /Ar Plasmas}

Adding a relatively small proportion of $\mathrm{Ar}(15 \%)$ to the $\mathrm{H}_{2}$ plasmas has a drastic effect on the electronic temperature, which goes down by a factor of two, as shown in figure $5 \mathrm{~b}$ (squares), which shows the results of the Langmuir probe measurements. The Ar atoms in the plasma lead to a more efficient thermalization of the free electron energy. In spite of the lower electronic temperature, a crossing of the $\mathrm{H}_{2}{ }^{+} / \mathrm{H}_{3}{ }^{+}$ionic ratio analogous to that described for pure $\mathrm{H}_{2}$ plasmas takes place at about $1 \mathrm{~Pa}$ (see figure 5a). Moreover, the predominant $\mathrm{Ar}$ containing ion is $\mathrm{ArH}^{+}$in all cases, and surprisingly high $\mathrm{Ar}^{2+}$ fluxes are also measured. In addition, with growing pressure, a remarkable decline in the flux of $\mathrm{Ar}^{+}$ ions reaching the cathode is observed and, in fact, for a pressure of $2 \mathrm{~Pa}$, it drops even below that of $\mathrm{Ar}^{2+}$. The appreciable changes in the cathode ion fluxes measured over the pressure range considered can be rationalized again with the kinetic model [22]. The most relevant processes and rate coefficients for this plasma are those included in table 1 for purely hydrogenic species, and the series of reactions listed in table 2 for reactions involving Ar. The probabilities of neutralization at the wall, not included in this table, are assumed to be one for all ions.

At first sight, the dominance of $\mathrm{H}_{2}{ }^{+}$ions for the lowest pressure is puzzling, since, as commented on above, these ions are expected to prevail only for electronic temperatures higher than $6 \mathrm{eV}$ (compare figure 2 with figure $5 \mathrm{~b}$ ). To account for the observations, a small fraction of high energy electrons, undetectable in the relatively coarse double Langmuir probe measurements, has to be assumed in the model calculations for this plasma. The appearance of $\mathrm{Ar}^{2+}$ ions, which are formed essentially through direct impact ionization of Ar atoms (R11) supports further this assumption, since this process has an energetic threshold of $48 \mathrm{eV}$. The existence of a high energy tail in the electronic energy distributions of DC glow discharges is well documented experimentally and theoretically $[26,27]$. Both, the $\mathrm{H}_{2}{ }^{+} / \mathrm{H}_{3}{ }^{+}$proportions and the measured $\mathrm{Ar}^{2+}$ flux can be accounted for by 
a small fraction of high energy $(>50 \mathrm{eV})$ non-thermal electrons, which vary from $2.3 \%$ at $0.7 \mathrm{~Pa}$ to $0.7 \%$ at $2 \mathrm{~Pa}$ (see circles in Figure $5 \mathrm{~b}$ ). The relative high concentrations of $\mathrm{ArH}^{+}$ are readily justified mostly by the efficient protonation reaction $\mathrm{R} 13$, with a rate coefficient [28] $\mathrm{k}=8.7 \times 10^{-10} \mathrm{~cm}^{3} \mathrm{~s}^{-1}$. However, the kinetic model of the glow, discussed thus far, cannot account for the marked decrease in the $\mathrm{Ar}^{+}$flux with growing pressure mentioned above. In order to explain this result, sheath collisions must be taken into account. Although, at the collision energies typical of the glow, the asymmetric charge exchange process R12 is unimportant as compared with reaction R13, the situation is inverted for the comparatively high collision energies of the sheath (up to $450 \mathrm{eV}$ ). Under this conditions, asymmetric charge exchange (R12), with a cross section $\sigma \approx 1.5 \times 10^{-15} \mathrm{~cm}^{2}[29]$ dominates over protonation (R13) [30]. The decrease of the $\mathrm{Ar}^{+}$signal due to asymmetric charge exchange can be taken into account approximately by assuming a Lambert-Beer attenuation [22]. With this correction, the experimental results are satisfactorily described by the model, as shown by the good accordance between the measurements (symbols) and the calculations (solid lines) in figure 5a.

\section{3. Air plasmas}

The main results of our investigation on air plasmas are summarized in figure 6 . Panels $a, b$ of this figure show the relative concentrations for the major neutral and ion species respectively, as a function of pressure in the 0.5-3 $\mathrm{Pa}$ interval. The experimental measurements and the predictions of the kinetic model are both displayed. The processes and rate coefficients considered in the model are listed in [21]. In figure $6 c$, the evolution of the electronic temperature is also represented. As expected, $\mathrm{N}_{2}$ is always the prevailing neutral species, but the concentrations of $\mathrm{NO}$ and $\mathrm{O}_{2}$ have opposite trends and, in the low pressure regime, $\mathrm{NO}$ even replaces $\mathrm{O}_{2}$ as the second most abundant constituent. The production of NO in air plasmas can be due either to collisions involving excited molecules and atoms [31-33] or to wall reactions [34-36]. In our low pressure plasmas, with small gas-phase collision frequencies, the latter mechanism is predominant. The key reaction for the heterogeneous production of NO involving oxygen atoms adsorbedon the stainless steel walls of our reactor, $\mathrm{O}(\mathrm{s})$, is assumed to be:

$$
\mathrm{N}+\mathrm{O}(\mathrm{s}) \rightarrow \mathrm{NO}
$$


with a rate coefficient $\gamma=4.9 \times 10^{-3} \mathrm{~s}^{-1}$ [34]. The production of NO at low pressures increases thanks to the enhanced $\mathrm{N}_{2}$ and $\mathrm{O}_{2}$ dissociation with growing $\mathrm{T}_{\mathrm{e}}$, which provides the atoms for reaction 1 . Note especially that the moderate variation in $\mathrm{T}_{\mathrm{e}}$ recorded in the experiments is enough to increase appreciably the rate coefficient for the electron impact dissociation of $\mathrm{N}_{2}$ (see figure 7a). This increase is much faster than that of the corresponding coefficient for the dissociation of NO, which constitutes the main sink for this species.

At the lowest pressures investigated, the ion flux reaching the detector is dominated by $\mathrm{N}_{2}^{+}$and $\mathrm{NO}^{+}$(see figure 6b). NO has by far the largest rate coefficient for electron impact ionization over the whole $T_{e}$ range, as shown in figure $7 \mathrm{~b}$, and this large ionization coefficient compensates for the smaller concentration of NO in the plasma. With increasing pressure, $\mathrm{NO}^{+}$, whose measured relative flux remains almost constant, prevails over the $\mathrm{N}_{2}^{+}$and $\mathrm{O}_{2}{ }^{+}$ions. The kinetic model can render the evolution of $\mathrm{O}_{2}{ }^{+}$with pressure, but yields too low $\mathrm{NO}^{+}$and too high $\mathrm{N}_{2}{ }^{+}$relative fluxes at the higher pressures. By analogy with the case of the $\mathrm{Ar} / \mathrm{H}_{2}$ discharge commented on in the previous sub-section, one can intuitively invoke a growing importance of sheath collisions transforming $\mathrm{N}_{2}{ }^{+}$into $\mathrm{NO}^{+}$to account for the observations. A likely candidate would be the reaction: $\mathrm{N}_{2}^{+}+\mathrm{O}_{2} \rightarrow \mathrm{NO}^{+}+$ NO, but as far as we know, available literature cross sections [37] stretch only to collision energies of $20 \mathrm{eV}$, as compared with typical sheath voltages of $400 \mathrm{eV}$; and the cross section values below $20 \mathrm{eV}$ are more than an order of magnitude lower than needed to account for the measured ion fluxes. Further measurements and calculations for this and other processes involving ion-molecule collisions of species containing $\mathrm{N}$ and $\mathrm{O}$ atoms in the $0-500 \mathrm{eV}$ range would certainly be helpful for the modeling of sheath processes in this type of plasmas.

\section{Conclusions and outlook}

In the previous paragraphs, we have shown various examples of characteristic abrupt changes in the chemical composition of glow discharges with pressure, due to different causes, including a marked variation in electronic temperature $\left(\mathrm{H}_{2}\right.$ plasmas), relevance of non-thermal electrons and sheath collisions $\left(\mathrm{H}_{2} / \mathrm{Ar}\right.$ plasmas), or the enhancement of molecular dissociation and wall reactions (air plasmas). Distinct processes can lead to similar characteristic composition changes in other plasmas. Preliminary results from our laboratory show, for instance, remarkable variations in the ionic composition of $\mathrm{H}_{2} / \mathrm{N}_{2}$ 
plasmas over a pressure range similar to those considered along this work. In this case, an increase in pressure leads to a clear dominance of $\mathrm{NH}_{4}^{+}$in the ion distribution. Wall reactions and a hierarchy of protonation processes in the glow are probably at the root of the observed behavior, which is being presently analyzed.

On closing, we would like to emphasize again the usefulness of a strategy combining an experimental diagnosis and simple kinetic models focused on distinctive composition changes, like those described throughout this article, for the identification of key features in the plasma chemistry of low pressure discharges.

\section{Aknowledgements}

This work has been funded by the Ministry of Science and Innovation of Spain under grants FIS2007-61686, FIS2010-16455 and CSD2009-00038. We are grateful to J. M. Castillo, M. A. Moreno and J. Rodríguez for technical support and advice. 


\section{References}

[1] Keshav S, Utkin Y T, Nishihara M, Bao A, Rich J W and Adamovich I V 2008 J. Thermophys and HeatTtrannsf. 22, 157.

[2] Herbst E 2005 J. Phys. Chem. A. 109, 4017.

[3] Petrie S, Bohme D K 2007 Mass spectrum. Rev. 26, 258.

[4] Majed T, Waite J H, Bougher S W, Yelle R V, Gladstone G R, McConell J C, Bhardwaj Jr A 2004 Adv. Space Res. 33, 197.

[5] Martín A, Menéndez A, Pereiro R, Bordel N and Sanz-Medel A 2007 Anal. Bioanal. Chem. 388, 1573.

[6] Gordillo-Vázquez F J, Herrero V J and Tanarro I 2007 Chem. Vapor Dep. 13, 267279.

[7] Han J G 2009 J. Phys. D Appl. Phys. 42, 043001

[8] Jacob W 1998 Thin Solid Films 326, 1

[9] Helmerson U, Lattemann M, Bolmark J, Ehiasarian A P and Gutmundson J P 2006, Thin Solid Films, 513, 1.

[10] Laroussi M 2005 Plasma Process. Polym. 2, 391.

[11] Tabarés F L, Tafalla D, Tanarro I, Herrero V J, Islyaikin A and Maffiotte C 2002 Plasma Phys. Control. Fusion 44 L37-L42

[12] Nakano T, Higashijima S, Kubo H, Yagyu J, Arai T, Asakura N and Itami K $2003 \mathrm{~J}$. Nucl. Matter. 313-316, 149.

[13] Tabarés F L, Rohde V and Asdex Upgrade Team 2004 Plasma Phys. Control Fusion 46, B381.

[14] Tanarro I, Ferreira J A, Herrero V J, Tabarés F L and Gómez-Aleixandre C $2009 \mathrm{~J}$. Nucl.Mater. 390-391, 696.

[15] Méndez I, Gordillo-Vázquez F J, Herrero V J and Tanarro I 2006 J. Phys. Chem. A, $110,6060-6$

[16] Tanarro I, Herrero V J, Islyakin A M, Méndez I, Tabarés F L and Tafalla D 2007 J. Phys. Chem. A 111, 9003

[17] Tanarro I and Herrero V J 2009 Plasma Sources Sci. Tech. 18, 034007.

[18] Qing Z, Otorbaev D K, Brussaard G J H, van de Sanden M C M and Schram DC 1996 J. Appl. Phys. 80, 1312-24.

[19] Lavrov B P, Melnikov A S, Käning M and Röpcke J 1999 Phys. Rev. E. 59, 3526.

[20] Lavrov B P and Pipa A V 2002 At. Spectrosc. 92, 709. 
[21] Castillo M, Méndez I, Islyaikin A M, Herrero V J and Tanarro I 2005 J. Phys. Chem. A, 109, 6255.

[22] Méndez I, Tanarro I, and Herrero V J 2010 Phys. Chem. Chem. Phys. 12, 4239-45

[23] Mihailov V, Gencheva V and Djulgerova R 2001 J. Phys. D: Appl. Phys. 34, 218590.

[24] Tserepi A D and Miller T A 1994 J. Appl. Phys. 75, 7231.

[25] KaeNune P, Perrin, J Jolly J, and Guillon J 1996 Surf. Sci. Lett. 360, L495.

[26] Gill P and Webb C E 1977 J. Phys. D, 10, 299.

[27] Bogaerts A and Gijbels R 1995 J. Appl. Phys. 78, 2233.

[28] Anicich V G 1993 J. Chem. Phys. Ref. Data, 22, 1469 and 2003 JPL publication 0319 NASA

[29] Amme R C and McIlwain J F 1966 J. Chem.. Phys. 45, 1224.

[30] Ervin K M and Armentrout P B 1985 J. Chem. Phys. 83, 166.

[31] Guerra V and Loureiro J 1997 Plasma Sorces Sci. Tech. 6, 373-385.

[32] Pintassilgo CD, Kutasi K and Loureiro J 2007, Plasma Sources Sci. Tech. 16, S115S122.

[33] Welzel S, Gatilova L, Ropcke J and Rousseau A 2007 Plasma Sources Sci. Tech. 16 $822-831$.

[34] Kline L E, Partlow W D, Young R M, Mitchel R R and Congedo T V 1991 IEEE Trans. Plasma Sci. 12, 278-285.

[35] Castillo M, Herrero V J, Méndez I, and Tanarro I 2004 Plasma Sources Sci. Tech. 13, 343.

[36] Kutasi K and Loureiro J 2007 J. Phys. D: Appl. Phys. 40, 5612-5623.

[37] Schultz RH and Armentrout PB 1991 J. Chem. Phys. 95, 121-129. 
Table 1: Main reactions for the kinetic model of $\mathrm{H}_{2}$ plasma.

For a complete list of reactions see Ref [15].

\begin{tabular}{|c|c|c|}
\hline & Reaction & $\mathrm{k}\left(\mathrm{cm}^{3} \times \mathrm{s}^{-1}\right)$ or $\gamma$ \\
\hline $\mathrm{R} 1$ & $\mathrm{H}_{2}+\mathrm{e} \rightarrow 2 \mathrm{H}+\mathrm{e}$ & $\mathrm{k}=1.75 \times 10^{-7} \times \mathrm{T}_{\mathrm{e}}^{-1.24} \times \mathrm{e}^{-12.6 / \mathrm{Te}}$ \\
\hline $\mathrm{R} 2$ & $\mathrm{H}_{2}+\mathrm{e} \rightarrow \mathrm{H}^{+}+\mathrm{H}+2 \mathrm{e}$ & $\mathrm{k}=3.00 \times 10^{-8} \times \mathrm{T}_{\mathrm{e}}^{0.44} \times \mathrm{e}^{-37.7 / \mathrm{Te}}$ \\
\hline $\mathrm{R} 3$ & $\mathrm{H}_{2}+\mathrm{e} \rightarrow \mathrm{H}_{2}^{+}+2 \mathrm{e}$ & $\mathrm{k}=3.12 \times 10^{-8} \times \mathrm{T}_{\mathrm{e}}^{0.17} \times \mathrm{e}^{-20.1 / \mathrm{Te}}$ \\
\hline $\mathrm{R} 4$ & $\mathrm{H}+\mathrm{e} \rightarrow \mathrm{H}^{+}+2 \mathrm{e}$ & $\mathrm{k}=6.50 \times 10^{-9} \times \mathrm{T}_{\mathrm{e}}^{0.49} \times \mathrm{e}^{-12.9 / \mathrm{Te}}$ \\
\hline $\mathrm{R} 5$ & $\mathrm{H}_{2}^{+}+\mathrm{H}_{2} \rightarrow \mathrm{H}_{3}^{+}+\mathrm{H}$ & $\mathrm{k}=2.00 \times 10^{-9}$ \\
\hline $\mathrm{R} 6$ & $\mathrm{H}^{+}+\mathrm{wall} \rightarrow 1 / 2 \mathrm{H} 2$ & $\gamma=1$ \\
\hline $\mathrm{R} 7$ & $\mathrm{H}^{+}+$wall $\rightarrow \mathrm{H}$ & $\gamma=1$ \\
\hline $\mathrm{R} 8$ & $\mathrm{H}_{2}{ }^{+}+$wall $\rightarrow \mathrm{H}_{2}$ & $\gamma=1$ \\
\hline $\mathrm{R} 9$ & $\mathrm{H}_{3}{ }^{+}+$wall $\rightarrow \mathrm{H}_{2}+\mathrm{H}$ & \\
\hline
\end{tabular}

Table 2: Additional main reactions for the model of $\mathrm{H}_{2} / \mathrm{Ar}$ plasma, which includes also those of Table 1. For a complete list of reactions see Ref [22].

\begin{tabular}{|l|c|c|}
\hline & Reaction & $\mathrm{k}\left(\mathrm{cm}^{3} \times \mathrm{s}^{-1}\right)$ \\
\hline $\mathrm{R} 10$ & $\mathrm{Ar}+\mathrm{e} \rightarrow \mathrm{Ar}^{+}+\mathrm{e}$ & $\mathrm{k}=2.53 \times 10^{-8} \times \mathrm{T}_{\mathrm{e}}^{0.5} \times \mathrm{e}^{-16 / \mathrm{Te}}$ \\
\hline $\mathrm{R} 11$ & $\mathrm{Ar}+\mathrm{e} \rightarrow \mathrm{Ar}^{++}+3 \mathrm{e}$ & $\mathrm{k}=2.58 \times 10^{-9} \times \mathrm{T}^{0.5} \times \mathrm{e}^{-47 / \mathrm{Te}}$ \\
\hline $\mathrm{R} 12$ & $\mathrm{Ar}^{+}+\mathrm{H}_{2} \rightarrow \mathrm{H}_{2}^{+}+\mathrm{Ar}$ & $\mathrm{k}=1.78 \times 10^{-11}$ \\
\hline $\mathrm{R} 13$ & $\mathrm{Ar}^{+}+\mathrm{H}_{2} \rightarrow \mathrm{ArH}^{+}+\mathrm{H}$ & $\mathrm{k}=8.72 \times 10^{-10}$ \\
\hline $\mathrm{R} 14$ & $\mathrm{ArH}^{+}+\mathrm{H}_{2} \rightarrow \mathrm{H}_{3}^{+}+\mathrm{Ar}$ & $\mathrm{k}=6.30 \times 10^{-10}$ \\
\hline
\end{tabular}




\section{Figure Captions}

Figure 1. (a) Relative ion concentrations as a function of pressure in $\mathrm{H}_{2}$ discharges. Symbols: Experimental data. Lines: Model predictions. (b) Symbols: Measured $\mathrm{T}_{\mathrm{e}}$. In this case, the dashed line is only to guide de eye.

Figure 2. Evolution with $\mathrm{T}_{\mathrm{e}}$ of the rate coefficients of the most significant reactions involved in the competition between $\mathrm{H}_{2}{ }^{+}$and $\mathrm{H}_{3}{ }^{+}$as mayor ion in low pressure $\mathrm{H}_{2}$ discharges (See Table 1).

Figure 3. Predicted evolution with time of ions and neutrals in $\mathrm{H}_{2}$ discharges, from the ignition of the discharge up to attainment of the steady state $(\sim 0.01 \mathrm{~s})$, for $0.8 \mathrm{~Pa}$ (a) and $2 \mathrm{~Pa}(\mathrm{~b})$. The $\mathrm{T}_{\mathrm{e}}$ values are those previously measured for these conditions. Symbols at the right of each panel are the corresponding experimental steady-state concentrations.

Figure 4. Lines: Model predictions for the variation of $\mathrm{H}$ and $\mathrm{H}_{2}$ concentrations with the probability of $\mathrm{H}$ recombination, $\gamma$, in the stainless steel surfaces of the reactor. Symbols: Experimental results (for $0.8 \mathrm{~Pa}$ ), leading to estimate the value $\gamma=0.03$.

Figure 5. (a) Relative ion currents in $\mathrm{H}_{2}+15 \%$ Ar discharge as a function of pressure. Symbols represent the experimental data and lines, the model predictions. (b) Measured $\mathrm{T}_{\mathrm{e}}$ (squares) and percentage of estimated proportion of high energy electrons needed to justify the measured distributions of ion currents (circles) (see text). The dashed lines in this case are only to guide de eye.

Figure 6. Distribution of (a) neutrals, (b) ions and (c) $T_{e}$ in air discharges, as a function of pressure. Symbols: experimental data. Lines: model predictions (a,b). The dashed line in (c) is only to guide de eye.

Figure 7. Dependence of the rate coefficients with $\mathrm{T}_{\mathrm{e}}$ for the most important (a) dissociative and (b) ionization reactions in air discharges, under the measured $\mathrm{T}_{\mathrm{e}}$ range. 
Figure 1
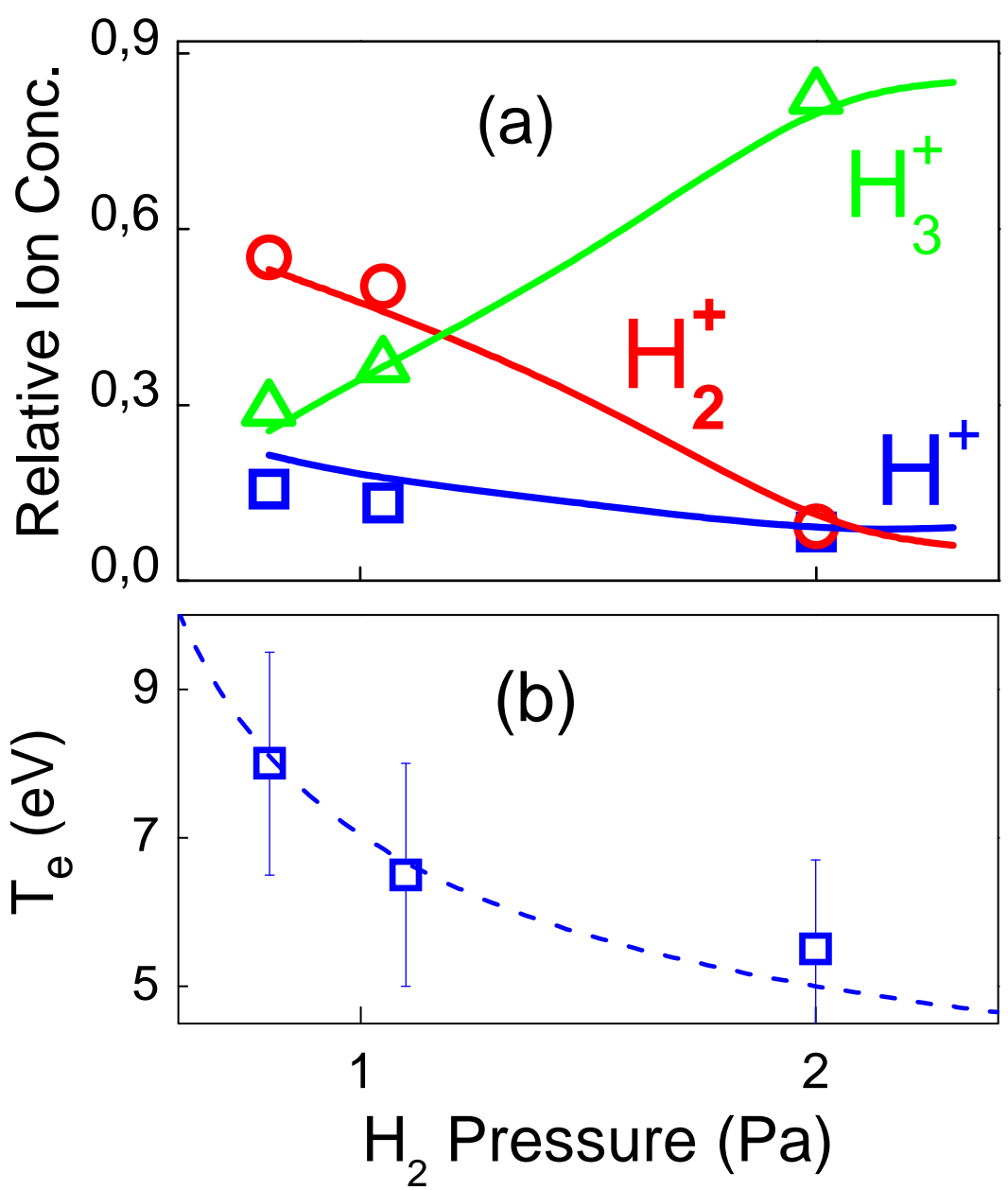

Figure 2

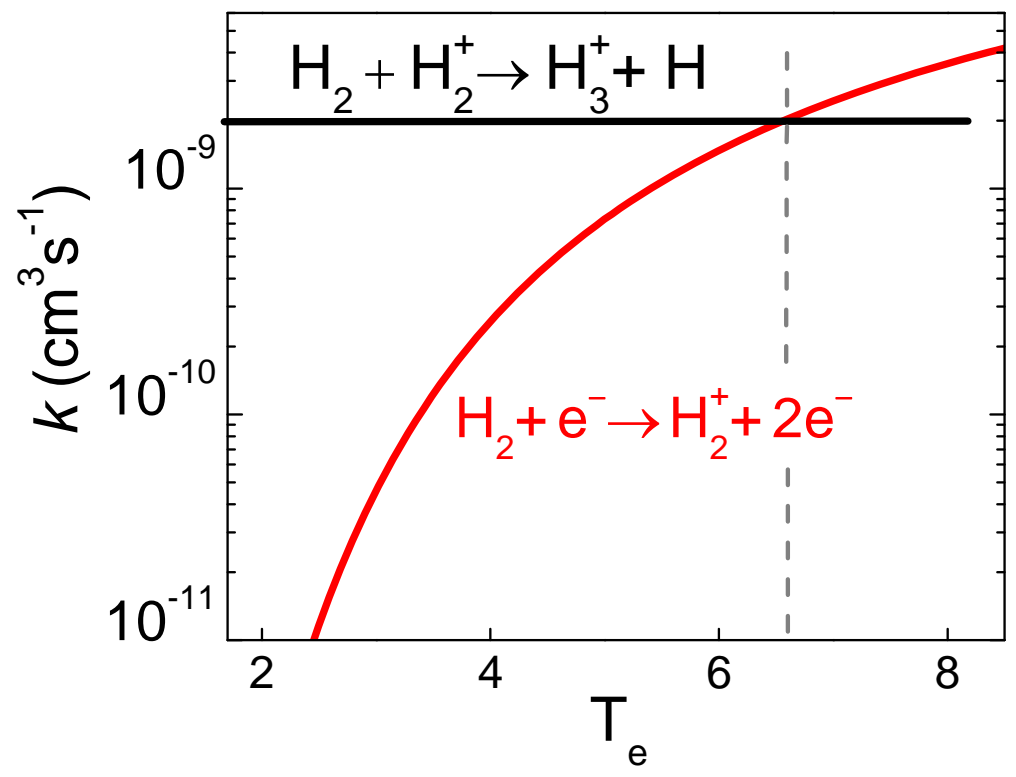


Figure 3

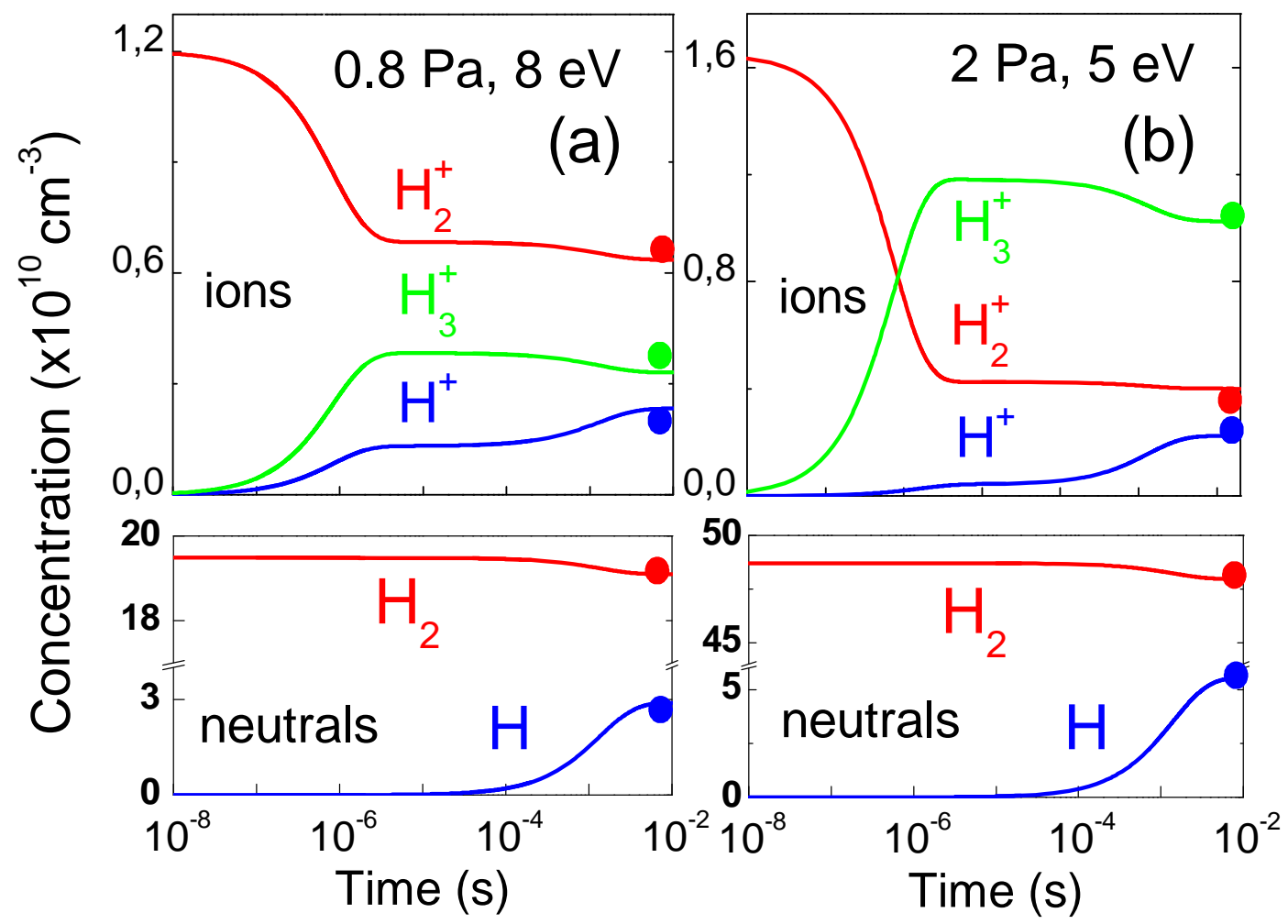

Figure 4

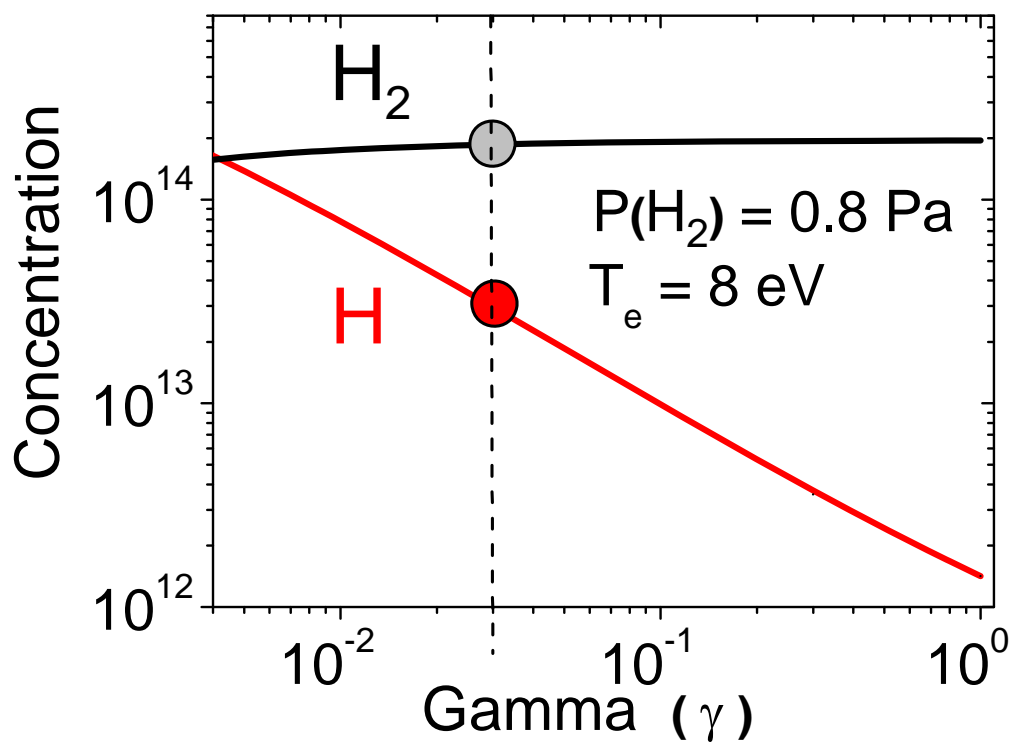


Figure 5

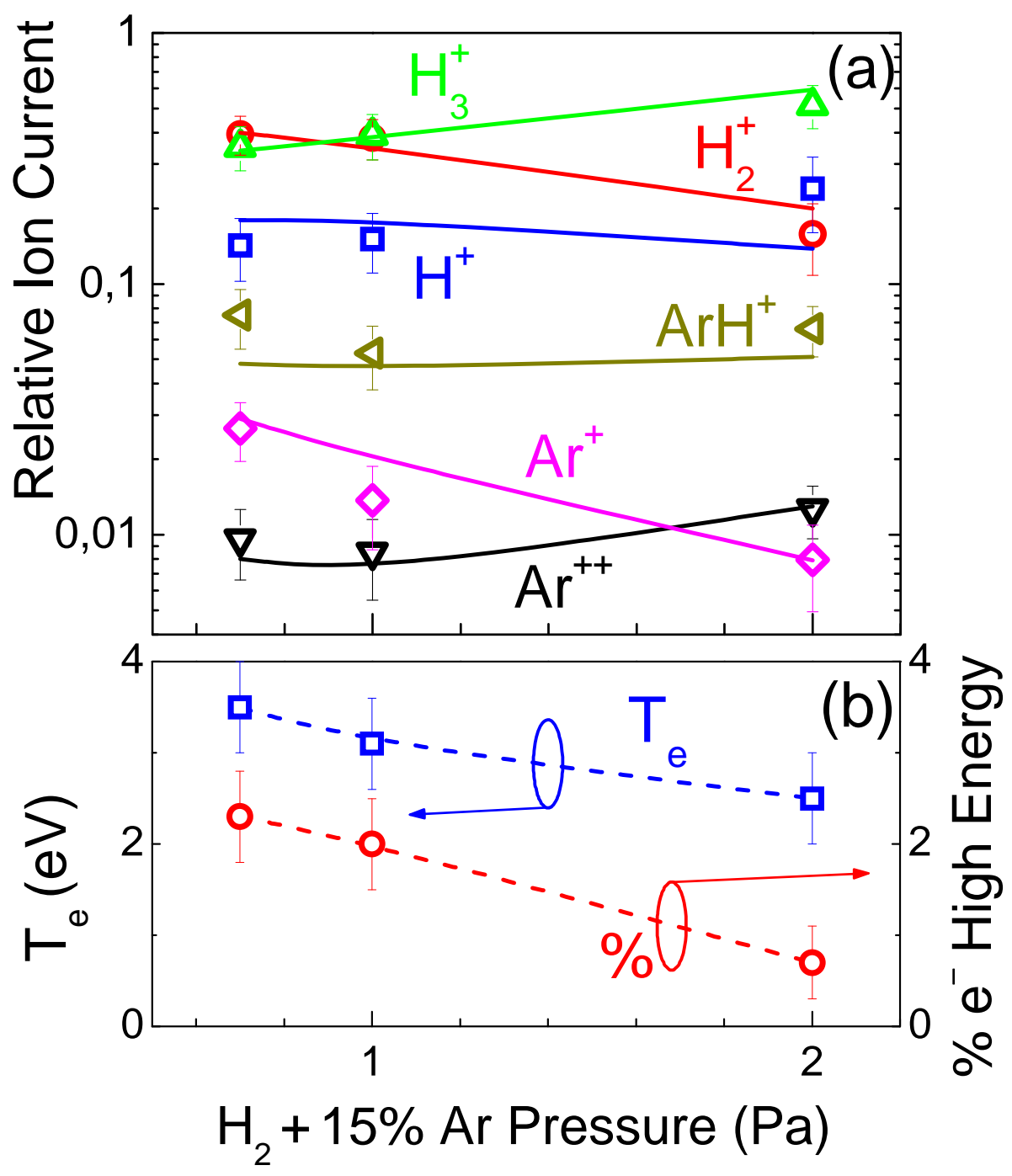


Figure 6

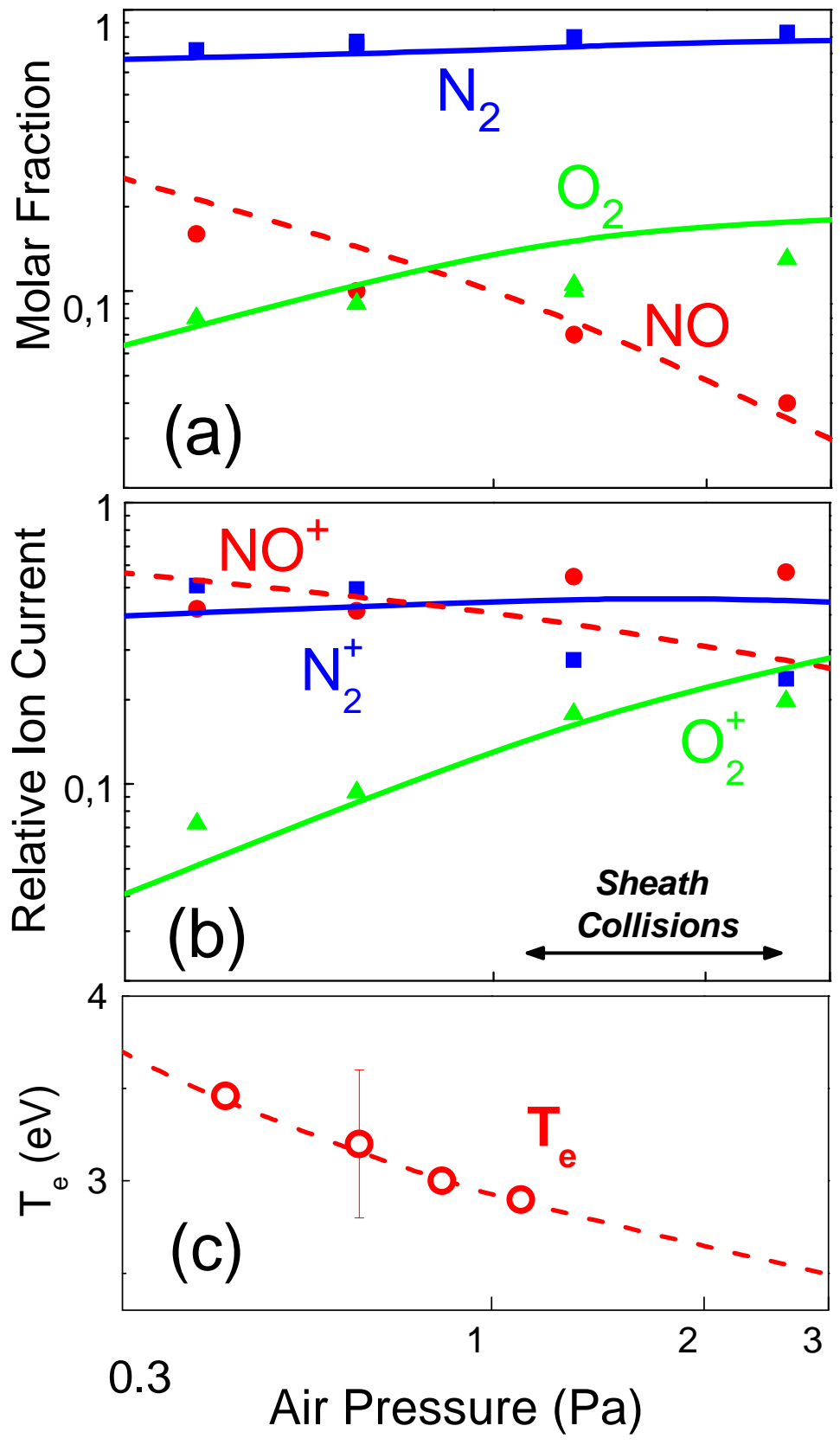


Figure 7
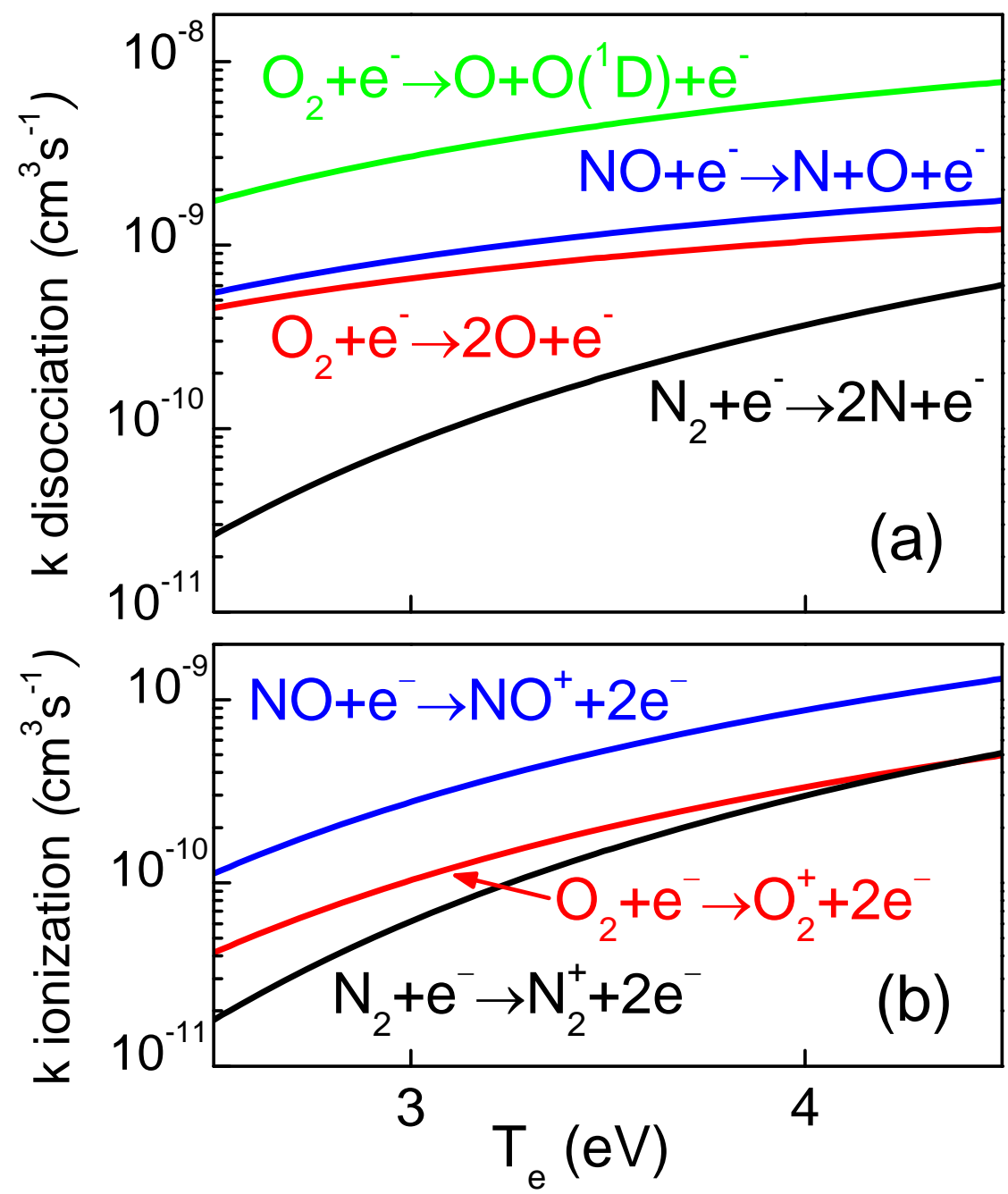